\title{
ELOGIOS FÚNEBRES, PEDRAS TUMULARES, SONHOS MUDOS: CÍRCULOS LITERÁRIOS E REINVENÇÃO RITUAL ENTRE POETAS BRASILEIROS (XIX-XX)
}

Francine Fernandes Weiss RICIERI*

\section{RESUMO}

O ensaio explora a recorrência, entre poetas brasileiros, de textos que se reportam à prática do elogio fúnebre, ou que recuperam de modo mais ou menos explícito a espécie tombeau, em diálogo com poemas franceses do final do século XIX. Pressupondo, com Maulpoix, um caráter coletivo primário para o poema lírico (a raiz do lirismo assentando-se na celebração), analisa-se o discurso encomiástico (elevado, laudatório, endereçado) discernível nos poemas abordados como portador de algo que não se resolve na expressão de um "eu", mas que parece indiciar uma operação coletiva de constituição de audiência, comunicação, contato, partilha. O poema, um gesto de interlocução, é dedicado, nesse sentido, a um poeta ilustre desaparecido, mas dedica-se, igualmente, ao estabelecimento de uma rede de afinidades e concepções de escrita que pressupõem a instauração de uma comunidade.

PAlavras-CHAVE: elogio fúnebre; tombeau; comunidade.

Um poema de Alphonsus de Guimaraens publicado em maio de 1898 no Jornal do Comércio de São Paulo (dois meses, portanto, após a morte de Cruz e Sousa - ocorrida em 19 de março) contém uma dedicatória em que se explicita o nome daquele que teria sido o principal poeta simbolista brasileiro. O título escolhido, contudo, é uma expressão grafada no plural e dela se pode nitidamente depreender a alusão a um grupo. O poema parece muito oportuno para se pensar o sentido

Professora da área de Estudos Literários, no Departamento de Letras da Universidade Federal de São Paulo/ UNIFESP, São Paulo, São Paulo, Brasil. Credenciada no Programa de Pós-Graduação em Letras, na mesma universidade.

E-mail: francinericieri@gmail.com 
específico de dedicatórias tais como aquela nesses versos enunciada, em especial quando consideramos sua recorrência e seu papel estratégico em um conjunto de escritos aos quais este texto pretende se referir.

"Poetas Exilados" escreve-se em terceira pessoa, contrariando aparentemente o que deveria ser a primeira e mais evidente marca formal de um poema "lírico". Organiza-se, também, a partir de um sequenciamento temporal narrativo, dependendo, ainda, da estruturação descritiva de um cenário que contribui de forma decisiva para a constituição de um imaginário de fantasmagoria. A cena se passa em um mosteiro antigo (sinos dobrando nos torreões, sem governo) e o que se narra é a progressiva aparição de um cortejo que constituirá a coletividade indiciada no título. Os poetas acorrem e, em sua diversidade, compartilham a falta de esperança e o silêncio.

Qualquerleitor familiarizadoà poética de Alphonsus de Guimaraens terá facilidade em reconhecer, no segundo quarteto, a recuperação de um dos grandes lugares comuns de sua escrita, tornado chave obrigatória de leitura pela crítica que ao escritor se dedicou: o biografema da prima-noiva morta. Contudo, neste poema em específico, a alusão vem convertida em aspecto genérico, indicado no plural, elemento adicionado à operação em processo - a composição descritiva de um corpo (uma corporação):

Poetas Exilados

A Cruz e Sousa

No mosteiro, de velha arquitetura, de era

Remota, vão chegando os poetas exilados.

A porta principal é engrinaldada em hera...

Os sinos dobram nos torreões, abandonados.

Uns são bem velhos e há moços na primavera

Da idade humana. Alguns choram mortos noivados.

Sem esperança, cada um deles tudo espera ...

Outros muitos têm o ar dos monges maus, transviados.

E ninguém fala. $\mathrm{O}$ sonho é mudo: e sonham, quando 
Ei-los todos de pé, extáticos, olhando

A branca aparição de hierático painel.

Chegaste enfim, magoado Eleito! Olham. Vermelhos

Tons de poente num fundo azul ... dobram-se os joelhos:

É Cruz e Sousa aos pés do arcanjo São Gabriel!

(GUIMARAENS, 1960, p. 513)

Ao contrário de outros casos explorados na sequência, o poema não se abre pelo retrato (físico ou literário) do morto em consideração . As três primeiras estrofes compõem uma cena em que se conjugam a arquitetura de um mosteiro antigo abandonado e a exuberância selvagem da natureza que o contorna. Nesse cenário perfila-se um cortejo de poetas à espera do homenageado (descrito apenas no terceto final). "Poetas exilados" é, por outro lado, uma operação de leitura: encerra-se com uma alusão explícita ao poema de Cruz e Sousa denominado "Anjo Gabriel”, cuja repercussão foi destacada por Andrade Muricy, no Panorama do movimento simbolista brasileiro (1973). Trata-se de um longo poema composto por 15 quadras e que descreve precisamente a aparição do anjo indicado em seu título. A figura igualmente fantasmagórica é insistentemente referida por seu brilho hierático e solene, que parece depender das ambiguidades e paradoxos deriváveis da insistência com que os versos recorrem ao adjetivo "claro":

$\mathrm{Na}$ calma irradiação das noites estreladas

Alto e claro aparece, alto, aparece, claro, Alvo, claro, no luar das estrelas prateadas,

No triunfal esplendor celestemente raro.

(CRUZ E SOUSA, 2000, p. 410)

1 Para ilustrar, poderia referir o soneto de Carlos D. Fernandes, "Ante o cadáver de Cruz e Sousa", que se organiza, desde o primeiro quarteto, pela composição de um "retrato" que é, a um tempo, literário e pessoal:

Ah! que eterno poder maravilhoso

Era esse que o corpo te animava,

E que a tu’alma límpida vibrava

Como um plangente carrilhão mavioso?

(FERNANDES apud MURICY, 1973, p. 641) 
A aparição do anjo, progressivamente encenada ao longo dos versos, evoca outros poemas do autor. Seria necessária, contudo, uma longa digressão para repertoriar o caráter metapoético das invocações por meio das quais Cruz e Sousa coloca em questão seus princípios compositivos, seus temas, seus recursos, suas obsessões. "Antífona" talvez bastasse, para se evitar o desvio, como alusão paradigmática, contribuindo para pensar um poema como "Anjo Gabriel", em que a estrofe final parece aglutinar um vasto conjunto de referências (admitindo leituras metapoéticas) que, por um lado, remetem à poética de Cruz e Sousa e, por outro, permitiriam recuperar "Poetas Exilados":

Mas quando o seu perfil nas amplidões floresce

$\mathrm{E}$ das asas se lhe ouve a música sonora,

Quando ele agita o gládio e as madeixas, parece

Que vai noctambular pelo Infinito afora.

E alto, branco, de pé, destacado no Espaço,

Eleito das Regiões de estranhas Primaveras,

Traça, com o gládio no ar, alevantando o braço,

Uma cruz de Perdão na mudez das Esferas!

(CRUZ E SOUSA, 2000, p. 412)

A escolha do vocábulo "Eleito" na alusão ao anjo parece sugerir superposição entre a figura central (Gabriel) e uma espécie de persona poética (ficcionalização da figura do poeta), em procedimento bastante recorrente em versos de Cruz e Sousa. Os diferentes representantes de poetas são com frequência aludidos como "eleito", "assinalado", sendo a primeira construção recuperada em "Poetas Exilados". Nos dois poemas, de resto, os personagens centrais (o anjo Gabriel e o poeta morto) são aparições hieráticas e mudas, ambos "Eleitos". Cada texto se dedica à enumeração dos elementos distintivos que os definiriam. Em Guimaraens, as variações cromáticas da última estrofe contribuem para compor a imagem do poeta morto (não associado apenas aos tons espiritualizantes que recobrem as imagens do anjo no poema aludido), o que já se indicia 
na ambivalência dos demais poetas que o aguardam (alguns velhos, outros moços; alguns chorosos, outros com ar de monges maus, transviados) sem que, contudo, se observe afastamento desse lugar discursivo, o elogio fúnebre. Elogia-se, portanto, também (no morto e naqueles que o homenagearam) o traço do exílio, aquilo que há de transviado, bem como um monastério daquele que é mau. Esse elemento levaria, ainda, ao elogio da exclusão, decisivo para a constituição dessa específica coletividade.

Cruz e Sousa foi homenageado por um grande número de textos que buscaram estabelecer a distinção do desaparecido, por meio de versos que, ao celebrarem o poeta, constituíram ainda um espaço comum (como em "Poetas Exilados"), alusivo a uma comunidade nas letras. O próprio Alphonsus de Guimaraens explicitou sua admiração pelo poeta em outros escritos, mas não me refiro aqui a demonstrações mais ou menos genéricas de admiração e deferência: busco, antes, delimitar essa forma em relação com rituais lutuosos. Escritores associados ao grupo da revista Rosa-Cruz, como Antônio Joaquim Pereira da Silva e Castro Meneses escreveram também textos em que se discernem aspectos do elogio fúnebre. No caso do soneto "Cruz e Sousa", de Castro Meneses (também participante do grupo "Arte Nova”), os quartetos definem o poeta morto aproximando-o a elementos da natureza e aos anjos, ao passo que os tercetos concentramse na morte do escritor, recuperando imagens como o "anátema" e o "emparedado", bem como os círculos dantescos do Inferno:

Rebramiu sobre ti um anátema eterno.

Mas, indômito e só, velho titã glorioso,

Transpuseste, sorrindo, os círculos do Inferno ...

E, esboçando na sombra o ríctus mais tristonho

Ficaste, como um deus, vencido e silencioso,

Emparedado, enfim, dentro do próprio sonho...

(MENESES, 1920 apud MURICY, 1973, p. 817)

Imagens alusivas ao inferno (com ou sem remissão a Dante), bem como a metáfora do sujeito emparedado em seu próprio sonho são 
pinçadas da própria obra de Cruz e Sousa (ou, por vezes, de imagens compartilhadas por outros poetas do período, como se pode observar no que diz respeito à obsessão pela Divina Comédia), razão pela qual reaparecem em elogios elaborados por diferentes autores. Em Antônio Joaquim Pereira da Silva, no soneto "Evocação a Cruz e Sousa”, recuperamse nas três primeiras estrofes elementos que ao mesmo tempo descrevem e exaltam a especialidade do poeta, enquanto o terceto final enuncia, na primeira pessoa do plural, o estabelecimento de uma relação com o desaparecido; uma relação que não é pessoal, mas coletiva:

Vimos dizer à terra em que repousa

Teu corpo, que teu gênio, Cruz e Sousa,

Vive florindo em nós cada vez mais!

(SILVA, 1928 apud MURICY, 1973, p. 671)

Na introdução da coletânea de ensaios L'éloge lyrique (2008), Alain Génetiot recupera a tópica do elogio (fúnebre ou de outra natureza) para considerar a eloquência demonstrativa ou epidíctica (ou seja, descritiva segundo uma perspectiva avaliativa e não neutra) em sua sobrevivência retórica desde a Antiguidade até a Renascença, lembrando o elogio como um dos exercícios preparatórios à composição de um discurso por oradores iniciantes. Desse ponto de vista, o pensamento sobre o elogio lírico (aproximando-o de gêneros encomiásticos) remeteria a formulações de Jean-Michel Maulpoix, que viu na ode a "forma-mãe do lirismo", já que, a despeito de suas atualizações históricas mais recentes, o lirismo não seria, em sua origem, expressão subjetiva de um eu mais ou menos biográfico, mas uma palavra coletiva, derivada do canto coral, com um enunciador que representaria a expressão de uma persona, algo como uma máscara de teatro. Assim, da antiguidade ao século XVIII, a primeira pessoa do poema cumpriria a função técnica de suporte de identificação patética,

2 Conferir “De l’ode encomiastique au chant du monde”. (GÉNETIOT, 2008, p. 5-14.) 
sendo o que se denominou, posteriormente, sujeito lírico, uma função retórica ou alegórica discernível nos textos:

\begin{abstract}
Assim a pessoa que profere o elogio não é um eu privado, mas ao contrário uma postura enunciativa simbólica, ou melhor, um corifeu que, como em Píndaro, torna-se o intérprete de uma comunidade cívica ou religiosa. Esses referentes antigos permitem deslocar a questão da sinceridade do encomiasta sempre suspeito de desempenhar uma encomenda interessada, especialmente no caso do mecenato em que o elogio não deve se transformar em solicitação e demanda por recompensa (J. Balsamo), em um serviço interessado que lançaria retrospectivamente uma sombra sobre a veracidade e o valor de seu objeto, fundamento último da perspectiva encomiástica. $\mathrm{O}$ sujeito enunciativo de um poema de louvor, portanto, importa menos que a comunidade que ele representa e confedera por sua palavra, inteiramente admirativa em relação ao objeto de seus louvores. Mais que sobre a identidade e a sinceridade do eu lírico, o enfoque é colocado no dedicatário, no endereçamento a um tu dado como exemplar ecujos méritos o poema detalha segundo os mesmos lugares já identificados pela tradição greco-latina. (GÉNETIOT, 2008, p. 9-10, tradução minha)
\end{abstract}

A propósito desta noção de uma comunidade que se confedera pela palavra, talvez seja representativo observar como o recurso a uma forma verbal plural já presente no poema anteriormente transcrito ("Vimos

\footnotetext{
Ainsi la personne qui profère l'éloge n'est pas un moi privé, mais au contraire une posture énonciative symbolique, ou, mieux, un coryphée qui, comme chez Pindare, se fait l'interprète d'une communauté civique ou religieuse. Ces référents antiques permettent de déplacer la question de la sincérité de l'encomiaste toujours suspect de s'acquitter d'une commande intéressée, notamment dans le cas du mécénat où l'éloge ne doit pas se transformer en sollicitation et en demande de récompense ( $\mathrm{J}$. Balsamo), en un service intéressé, ce qui jetterait rétrospectivement une ombre sur la véridicité et la valeur de son objet, enjeu ultime de la perspective encomiastique. Le sujet énonciateur d'un poème de louange import donc moins que la communauté qu'il représente et fédère par sa parole, toute entière admirative envers l'objet de ses louanges. Plus que sur l'identité et la sincérité du je lyrique, l'accent est mis sur le dédicataire, l'addresse à un tu donné comme exemplaire et dont le poème détaille les mérites selon les mêmes lieux déjà identifiés par la tradition gréco-latine.
} 
dizer à terra em que repousa/ Teu corpo"), reaparece em um poema de Nestor Vítor, em que, ao contrário do que se vem descrevendo, organizase o elogio a partir de um posicionamento que parece bem mais pessoal entre a voz em enunciação e a figura do homenageado (o que retomaria, portanto, a proximidade entre os dois poetas, em vida):

\section{A Cruz e Sousa}

Não gemem na minh'alma árias langues de morte, Antes vibram clarins e há alvoroços de guerra; Somente, um tal tremor faz-me vibrar tão forte Que sou, todo, um soluço a ansiar sobre a Terra!

Não! os que, como tu, morrem sacramentados Com a Extrema-Unção da glória, e andaram impolutos, No casulo do Sonho, esperando, calados, A Vida após a Morte, a Pompa Real nos Lutos,

Não nos fazem pensar na frialdade ao peito De uma laje medonha, ao cair exausto: Vê-se neles o gesto augusto de um Eleito ... Ouvem-se hosanas no ar, abrem-se céus em faustos! [...] (VÍTOR, 1900 apud MURICY, 1973, p. 333).

Apesar de, na primeira estrofe, o luto formular-se em primeira pessoa, recusam-se imagens líricas em favor de um imaginário bélico. Ao morto associam-se conotações de consagração e glorificação a partir de referenciais religiosos, estabelecendo-se, na terceira estrofe, um elo que vai além daquele que une admirador e admirado: "Ouvem-se hosanas no ar, abrem-se céus em faustos!” A relação, portanto, entre o poeta vivo e aquele que desapareceu atravessa a condição mortal e repercute em uma aproximação que se estende para além da morte, irmanando o Eleito, os seres da "Vida após a Morte" e aquele que canta como um "nós" (uma coletividade, portanto, a que essa voz se alia). A laje fria imposta pela 
morte desfaz-se em um conjunto de gestos que atravessam o que seria a terminalidade e abrem para uma interlocução representada como estando em processo, de algum modo perene, de algum modo presentificada na retomada de cada leitura. Por outro lado, o poema de Nestor Vítor evoca o morto, atualizando-o como "tu": "os que, como tu, morrem sacramentados". Inserido na cena enunciativa, aquele que se elogia passa a participar textualmente da comunidade que funda ou congrega no campo do imaginário. E, a despeito da recorrência do vocabulário religioso, algumas formulações ("extrema- unção da glória”, "impoluto no casulo do Sonho") conferem alguma ambiguidade à "Vida após a Morte", ou à "Pompa Real nos Lutos".

Obviamente, seria impreciso entender que esse complexo de sentidos diga respeito apenas aos elogios fúnebres dedicados a Cruz e Sousa. Paulo Araújo, membro ativo também do grupo da Rosa-Cruz, escreveu "Saturnino de Meireles" (o nome do homenageado aparece no título, enquanto a dedicatória refere-se "Aos meus companheiros da RosaCruz”). Sobre Araújo, Andrade Muricy informa tratar-se de um assíduo poeta "marial", profundamente religioso, o que se pode observar, de resto, na linguagem litúrgica, bem como nas imagens selecionadas para integrar os poemas citados. Já a abertura do poema revela uma perspectiva fortemente devocional a propósito da morte do poeta mencionado no título:

Alma que hoje nos céus de novo brilha,

Cheia de glória e de beleza tanta,

Voltou à paz de Deus de que era filha

Na sexta-feira da Semana Santa...

(ARAÚJO, s.d. apud MURICY, 1973, p. 824)

A estrofe final também é muito elucidativa:

E, porque teve um coração formoso,

Dos sofrimentos carregando a cruz,

Veio a expirar, sereno e luminoso,

Nessa semana em que morreu Jesus..."

(ARAÚJO, s.d. apud MURICY, 1973, p. 824) 
Tomado por metáforas pias, quase sem espaço para tensionamentos, o poema talvez sirva de contraponto ao que se indicou a propósito dos versos de Nestor Vítor (com sua “extrema-unção da glória”) ou aos poetas que nos versos de Alphonsus de Guimaraens "têm o ar dos monges maus, transviados”. Ainda que se possa indicar como uma espécie de lugar comum retórico do elogio fúnebre a alusão à imortalidade da obra (que se opõe à mortalidade do homem) há uma clara distância entre os versos de Paulo Araújo e os de Vítor. Ao recusar a posição de executor singular de árias de morte ("Não gemem na minh’alma árias langues de morte"), deslocando a ação para clarins e alvoroços de guerra, a voz em enunciação já desviava a cena, na primeira estrofe do poema, do espaço metafísico de uma alma singular, para o campo aberto em se desenha uma batalha. Paralelamente, o tremor individual, assinalado na mesma estrofe converte-sena potência de um soluço que se estende por toda a Terra.

Esses diferentes poemas, contudo, em geral, mantêm-se em uma dicção confessional e mesmo o elogio proferido por Nestor Vítor (em 51 quadras) encerra-se com um distante encontro post mortem das almas dos dois amigos. Pensando em conjunto os textos dedicados à morte de Cruz e Sousa, alguns traços recorrentes talvez possam ser explicitados: a ocasião que dá origem aos elogios irmana poetas já consagrados e homens de letras mais ou menos obscuros; no caso de Nestor Vítor, talvez se possa discernir a busca pelo reconhecimento da posição de herdeiro espiritual ou literário do poeta morto (busca que não estaria ausente dos demais textos); a tribuna em que se constituem os jornais em que se publicam os versos enlutados simultaneamente abre espaço à manifestação de estima e compadecimento bem como ocasião de exposição e reconhecimento daquele que escreve; em acréscimo, a inclusão de outros personagens em dedicatórias e referências (como a inclusão dos companheiros da revista Rosa Cruz) faz supor um conjunto de estratégias enunciativas que constituem mecanismos de coesão de grupo, mecanismos de pertencimento comunitário.

Joël Castonguay Bélanger, referindo-se à literatura funerária desde a França da Renascença, arrola alguns dos elementos presentes no parágrafo 
anterior (entre outros) para descrever uma prática de publicação coletiva dedicada a mortos ilustres (membros da família real, servidores do Estado, médicos, juristas, poetas etc.), cuja primeira manifestação teria ocorrido em 1531 e que teria progressivamente se tornado cada vez mais ritualizada, conjugando ao mesmo tempo o aspecto cerimonial dos funerais (em sua função de reunir os integrantes de um grupo ou de uma comunidade) e o aspecto monumental do túmulo real a partir de cujo modelo o poema seria elaborado e ao qual equivaleria virtual e concretamente:

Prática literária bastante difícil de circunscrever por causa da ausência de regras e de critérios genéricos específicos, o Tombeau (ou Tumulus) aparece acima de tudo como um dispositivo editorial e estrutural que integra no mesmo espaço textual diferentes formas poéticas reconhecidas. Embora a qualificação tombeau às vezes sirva para designar um poema individual [...], o termo é mais geralmente usado para designar uma compilação coletiva que combina peças fúnebres de formas poéticas diversas como o soneto, o epitáfio, a ode, o dístico, a elegia, etc. (BÉLANGER, 2002, p. 56, tradução minha)

O autor recorre, ainda, a Amaury Fleges (2000) para observar que “ [...] bastaria analisar em detalhes a lista de participantes das diferentes coletâneas para explicitar a rede de solidariedades - e de hierarquias - no interior da comunidade literária” (FLEGES, 2000, p. 84 apud BÉLANGER, 2002, p. 62, tradução minha) ${ }^{6}$. Ora, os poemas fúnebres dedicados a Cruz e Sousa encontram-se dispersos na imprensa e foram sendo publicados ao longo dos meses que se seguiram a sua morte. Alguns

$4 \quad$ Ver BÉLANGER, 2002, p. 57.

5 Pratique littéraire plutôt difficile à circonscrire en raison de l'absence de règles et de critères génériques spécifiques, le Tombeau (ou Tumulus) apparaît avant tout comme un dispositif éditorial et structurel qui intègre en un même espace textuel différentes formes poétiques reconnues. Bien que l'appellation "tombeau” serve parfois à designer um poème individuel [...], le terme sert plus généralement à designer un recueil collectif réunissant des pièces funèbres de diverses formes poétiques comme le sonnet, l'épitaphe, l’ode, le distique, l'élégie, etc.

6 “[...] suffirait d'analyser en detail la liste des participants aux différents recueills pour faire apparaître le réseau des solidarités - et des hierarchies - au sein de la communauté littéraire”. 
passaram a compor, posteriormente, livros organizados segundo outros critérios, em diferentes datas, o que certamente impede de pensá-los nos mesmos termos da prática editorial do tombeau, tal como a descrevem Fleges e Bélanger. No entanto, o caráter circunstancial daqueles elogios fúnebres (sua proximidade temporal da morte do homenageado, além da proximidade intelectual ou afetiva entre os envolvidos) também parece servir “ $[. .$.$] à enunciação de valores comuns, de princípios nos quais$ se reconheciam - ou contra os quais lutavam - os poetas reunidos", (BÉLANGER, 2002, p. 62, tradução minha)

Ainda que não reunidos os poemas em um mesmo objeto/livro, os enlutados de Cruz e Sousa reúnem-se em uma comunidade literária e, nesse caso como naquele, não é difícil perceber um deslizamento do elogio fúnebre em direção ao elogio do grupo, como o ensaio assinala ocorrer, em especial nos tombeaux publicados em honra de homens de letras. Por outro lado, a referida tensão entre o aspecto cerimonial dos funerais (reunião de comuns) e o aspecto monumental do túmulo, ainda que, com alguma imaginação pudesse ser associada a "Poetas exilados" contribui também para o afastamento entre as duas práticas em discussão. Nesse sentido, se a recuperação da prática do tombeau (ou tumulus) parece útil para pensar alguns aspectos dos poemas anteriores, só encontraremos em Eduardo Guimaraens um diálogo mais evidente com o que pudessem ser as pretensões do gênero em ser reconhecido tanto como forma monumental quanto como discurso, ou sua estruturação como metáfora arquitetural.

Em “Túmulo de Alceu Wamosy”, ainda ecoando o tema da imortalidade da obra em contraposição à mortalidade (e precariedade) dos homens, os versos dirigem-se ao poeta morto (em segunda pessoa, esquivando-se a voz em enunciação em constituir um eu que se pudesse designar como o centro do processo poético em curso), recorrendo a imagens como lápide e pedra que, juntas, podem permitir a associação

\footnotetext{
7 “[...] à l'énonciation de valeurs communes, de principles dans lesquels se reconaissaient - ou contre lequels luttaient - les poétes réunis".
} 
à peça arquitetônica túmulo, que se ergue simbolicamente por sobre a lacuna deixada pela perda do parceiro literário. Assim, a pedra sublinha a impossibilidade de retomada do legado que possa ter sido deixado incompleto (a página em branco do Poema), mas, ao fazê-lo, inscreve (operação mais duradoura que aquela por meio da qual o sonho se converte em flores - recuperando-se um campo imagético alusivo à escrita literária e certamente a uma das obsessões centrais na poética de Guimaraens, Charles Baudelaire) por sobre o perecível os signos de uma imortalidade de letras. Louvores que não murcham se grafados sobre a pedra tumular/ poema:

Túmulo de Alceu Wamosy

Sobre a triste angústia suprema, gélida, a lápide tombou.

Página em branco do Poema que a tua mão não terminou. Mas sê tranquilo: entre os louvores que Amor na pedra eternizou, não murcharão jamais as flores do sonho que te coroou. (GUIMARAENS, 1944, p. 372).

O título reduplica-se na forma "a lápide tombou" (tombeau), que parece remeter mais diretamente não ao tombeau como a prática renascentista que buscamos circunscrever nas páginas anteriores. Tombeau, em Eduardo Guimaraens, desde a publicação da Divina Quimera (1916) implica relação com alguns poemas franceses nos quais a prática do tombeau adquire alguns sentidos mais específicos. Insere-se Guimaraens, nesse caso, em um diálogo que é estabelecido simultaneamente com o poeta próximo (o amigo morto, Alceu Wamosy) e com o distante (cronologicamente), o que sugere que o caráter de "poesia de circunstância" talvez precise ser reconsiderado ou retocado. Ainda que evocando (na sutileza do título e na recuperação da dualidade monumento/cerimônia) versos distantes 
no tempo e no espaço, o poema será, paralelamente, o registro de uma proximidade, uma proximidade por eleição em que o espaço do comum se amplia para além do círculo direto da convivência física, abrindo-se para a experiência do literário como desafio às fronteiras.

Na Divina Quimera, toda a segunda sessão do livro (composta por nove poemas) ${ }^{8}$ parece de algum modo relacionável à prática do elogio fúnebre ou, no caso específico de alguns dos poemas, a uma reformulação do que Jean-Nicolas Illouz, referindo-se especificamente a Mallarmé, denominou "uma poética do tombeau" ". Em um livro organizado em seis partes e estruturado por meio de um declarado diálogo entre poéticas, a segunda sessão parece desempenhar um papel específico na economia da obra. Teríamos, à primeira vista, um conjunto de homenagens prestadas a alguns escritores e mesmo a Chopin. Pensar essas homenagens como reformulações do elogio fúnebre enquanto gênero de circunstância parece, contudo, uma abordagem de algum modo insuficiente, já a partir do primeiro desses poemas, denominado "Dante" (poeta evocado já na escolha do título, Divina Quimera).

Desde a primeira estrofe, o poema recupera imagens associáveis ao universo dantesco ("desespero eterno", o "inferno"), além de encarecer a beleza da linguagem e o caráter contraditório dos versos referidos. Cabe à estrofe final, contudo, explicitar um elemento que percorre o poema como um todo e mesmo essa sessão do livro, em sua integridade. A disposição dos elementos que constituem a escrita do poeta homenageado é mais

8 Para uma análise mais detida das possíveis interpretações do complexo sistema de epígrafes e alusões que compõem o livro, remeto a tese de doutorado finalizada em 2017, que aborda, também, o amplo leque de referências que talvez pudessem ser associadas à simples escolha de um conjunto de nove poemas para integrar essa sessão do livro. Na tese, transcreve-se, de resto, um poema dedicado a Fausto, publicado na revista Fon-fon como destinado a compor o livro e que dele foi excluído, quando da publicação, o que talvez contribua com a consideração de uma busca de adequação do livro a padrões numéricos em que se implicitam alusões intertextuais. (ANTONELLI, 2017).

9 Conferir: "Fragments d'un discours sur la mort: Éloge Funèbre, tombeaux et écriture du deuil dans l'oeuvre de Mallarmé". (ILLOUZ, 2008, p. 375-390). 
que um louvor ao projeto de escrita alheio, configurando, em acréscimo, uma adesão, a afirmação de uma proximidade. Mais que um poeta morto (distância extrema, inviabilização eventual de encontro), Dante é um elemento do cânone assumidamente acionado e interpretado segundo uma dinâmica pessoal (um projeto peculiar de escrita) que indicia sua atualização no livro em questão:

Dante! - Quero-o, porém, mais doloroso e terno, mais humano, a compor, torturado e feliz, sob a angústia mortal do seu secreto inferno, uma canção de amor em louvor de Beatriz! (GUIMARAENS, 1916, p. 48.)

No modo de estruturação do livro de 1916, a “canção de amor" em que se narra uma progressiva trajetória do eu poético em direção à mulher amada $^{10}$ permanece reputada como central ao modo de organização do livro ${ }^{11}$, a despeito de estudos mais recentes, como o de Ellen G. B. Antonelli empreenderem aproximações parciais entre a estrutura do livro e formas musicais como a sinfonia, a sonata e a fantasia. Essas aproximações certamente constituem ganhos na consideração das tensas relações entre as partes que compõem o volume. Se, contudo, de um plano geral, "temos o amor como motor do canto" (ANTONELLI, 2017, p. 86), da prática do elogio fúnebre pareceria permanecer atuante o elemento que temos reputado central na consideração dos objetos em análise: a constituição de uma comunidade nas letras. Nas letras e no campo musical, como pode sugerir o segundo poema da Parte II, cujo título remete a Chopin.

10 Para Maria da Glória Bordini, não seria aceitável uma associação entre a figura feminina presente na obra e um ideal inalcançável de amor. A quimera do título, sem entrarmos aqui na consideração de relações com Nerval, denunciaria "a posição do Poeta ante a mulher, incompreensível mistura de força, sensualidade e astúcia, refúgio extremado na maternidade e umbral da morte na relação sexual”. (BORDINI, 1980, p. 75 apud ANTONELLI, 2017, p. 83).

11 Conferir o verbete dedicado ao poeta no Pequeno Dicionário da Literatura do Rio Grande do Sul, de Ana Maria Lisboa de Mello (1999, p. 65-66). 
Ao homenagear aqueles que considera seus mestres, ou aqueles cujos recursos estéticos ou compositivos pretende atualizar em sua própria escrita, o poeta gaúcho está também delimitando as forças centrais de seu projeto poético. Temos um exercício metapoético, nesse sentido, cuja interpretação parece poder ser melhor explorada também a propósito do único, dentre os poemas da Divina Quimera, que apresenta um título em que se enuncia a palavra "túmulo", o terceiro da sessão em discussão:

3

\section{TÚMULO DE BAUDELAIRE}

Um anjo, que possui uma espada de chama, hirto e pálido, à fronte um halo virginal, guarda o Túmulo, junto ao mármore imortal, a que o Poeta desceu; cego de luz e lama.

Outro, que às mãos desfralda o ardor de uma auriflama, olha, cismando, o azul profundo como o mal; e Lúcifer, enfim, magnífico e fatal, tem à boca a revolta em que a blasfêmia clama.

Entre a aridez da terra e a solidão noturna, fundo abismo, do espaço ao lúgubre esplendor, fendem-se do Desejo as largas fauces de urna.

$E$ as Danaides, de aspecto envelhecido e eterno, tentam encher em vão esse tonel de horror! Ora, lá dentro, o Céu! Uiva, lá dentro, o Inferno! (GUIMARAENS, 1916, p. 50.)

O soneto com que se abriu este ensaio, denominado "Poetas exilados”, inseria, em seu quarteto final, uma operação de leitura por meio da qual Alphonsus de Guimaraens lia “Anjo Gabriel”, imagem aurática em que Cruz e Sousa parece ter lido (a partir de um referencial que seria da ordem do sagrado) alguns aspectos relativos a uma atividade profana - a literatura. Mas os poetas exilados daquele poema, eram também "monges maus", oscilando entre o hierático e o transviado e o título do poema 
evocava, vagamente, um tom que parece remeter ao título de outro poema, do contemporâneo Maranhão Sobrinho ("Poetas malditos") que, por sua vez , recupera Verlaine em texto homônimo e anterior - que se constitui como operação de leitura conhecida e vastamente comentada. Borges, em 1951, sentenciava: "O fato é que cada escritor cria seus precursores. Seu trabalho modifica nossa concepção do passado, assim como há de modificar o futuro".

Dispenso-me, aqui, de um levantamento minucioso da presença de Baudelaire na poesia de seu tradutor ${ }^{12}$ Eduardo Guimaraens, limitandome a observar que os trabalhos de Antonelli e Meirelles dedicam-se a cuidadosos estabelecimentos de epígrafes, citações, recuperações imagéticas, coincidências vocabulares, além de apontar a incorporação de tensões e dualidades (também estruturais) tornadas operantes de formas específicas, ao menos na Divina Quimera. Não poderia deixar de lembrar, contudo, que o quinto poema dessa parte II do livro de Guimaraens denomina-se "De profundis clamavi", expressão que a um tempo remete a um dos sete salmos penitenciais (usualmente adotados como oração fúnebre) e ao poema de mesmo título, de Baudelaire (XXX, em As flores do mal). Em Guimaraens, uma voz se dirige ao criador em brado "maldito" proferido pelo lábio ardente de um precito “ [...] que em vão interrogou a sombra do infinito". O diálogo com Baudelaire revela-se de modo ainda mais marcado nos dois versos finais, em que se flagra a ambivalência da condição humana, oscilação entre o sofrimento (paradoxalmente associado ao Éden) e o gozo (associado ao Inferno).

Em “Túmulo de Baudelaire” um anjo dá abertura à cena: um anjo postado diante do túmulo (atualizando a figuração do monumento) em

12 Ricardo Meirelles sintetiza a atuação de Guimaraens como tradutor: o Canto V (do Inferno, de Dante), as Fêtes Galantes, de Verlaine, Heine, Tagore, além de poemas esparsos italianos, franceses e hispano americanas, com destaque para 81 poemas de As flores do mal. No primeiro e no último caso, suas versões costumam ser lembradas por sua excelência no momento de sua produção. Ainda segundo Meirelles, até 1928, ano de sua morte, Guimaraens tinha sido o tradutor do maior número de poemas do livro citado, de Baudelaire. (MEIRELLES, 2003) 
visitação simbólica por um poeta (diante do Poeta, Baudelaire). Donaldo Schüler encontrou no relato bíblico a descrição de querubins com espadas de fogo guardando a entrada do Jardim do Éden, após a expulsão do homem, evitando seu acesso à arvore da vida ${ }^{13}$. Em sua análise, o Outro seria o poeta postado diante do túmulo, em companhia do primeiro anjo e de um segundo, Lúcifer. Comentando o mesmo poema, Ellen Antonelli recorre a exegetas da obra de Baudelaire para explorar contradições e ambivalências discerníveis em seus escritos. Apropria-se, ainda, de relações com Dante e mesmo com Mallarmé ${ }^{14}$, indiciados em momentos específicos do poema em discussão. Tais relações permitiriam estabelecer sentido em especial para os tercetos que encerram o poema, em tormento e turbulência.

Sem necessariamente divergir das análises referidas, salientaria que o primeiro quarteto sela, em "mármore imortal", o destino do primeiro Poeta, de modo que, na dinâmica do poema, as três demais estrofes mobilizam-se em torno das operações tensas e ambivalentes por meio das quais Outro poeta se revela. Morto Baudelaire antes da escrita deste tombeau, quem cisma o azul tendo às mãos o ardor de uma auriflama, "entre a aridez da terra e a solidão noturna" senão o poeta que se inscreve no poema ritual/monumento? Diante da pedra tumular (edificando em palavras uma pedra tumular), este Outro poeta é o ser diante do abismo e a ele parece associar-se o Desejo cujas tensões aparecem descritas a partir da imagem de uma urna de largas fauces que Danaides dedicam-se inutilmente a encher.

Seria redutor, sem dúvida, apagar em especial do terceto final a sobreposiçãoentre os dois $\mathrm{P} /$ poetas: mas se o anjo do verso inicial guarda/ evita alguma operação ou movimento, não seria antes o movimento de fora

\footnotetext{
13 Ver SCHÜLER, 1986, p. 16.

14 O quarto poema da sessão da Divina Quimera em discussão denomina-se "A Stéphane Mallarmé”. Foi publicado na imprensa antes de integrar o volume, apresentando três versões conhecidas. No poema em discussão, a relação com a poética de Mallarmé também se faz notar. Ver ANTONELLI, 2017.
} 
para dentro, aquele por meio do qual o poeta discípulo se atire para dentro da escrita outra e com ela se possa fundir? Não seria precisamente por que o poeta visita o túmulo e o refaz simbolicamente em poema que ele profana a pureza ou a univocidade daquilo que ali se guarda - constituindo, no processo, a possibilidade de fazer-se poeta, enquanto se constitui Outro - mesmo que dependente daquele que erigiu como Poeta (ou Poetas como indicia a estrutura da Divina Quimera)? A segunda sessão da Divina Quimera, nesse sentido, como poderíamos observar também a propósito de Broqueis, de Cruz e Sousa, parece dotar o livro de uma invocação, que remeteria, de algum modo, a textos épicos. Em Broqueis, "Antífona” abre o volume convocando as forças cósmicas que fecundariam aquele projeto de escrita. Na Divina Quimera, exercício similar seria estabelecido, na medida em que toda a segunda sessão restabeleceria o que Maulpoix teria assinalado como sendo um caráter coletivo primário para o poema lírico (a raiz do lirismo assentando-se na celebração). Ainda que o livro possa ser organizado a partir da entrecortada enunciação de uma história de amor, essa sessão não se resolve na expressão de um "eu", nem na enunciação da devoção amorosa, parecendo, antes, indiciar uma operação coletiva de constituição de audiência, comunicação, partilha. $\mathrm{O}$ poema (ou o livro de poemas), um gesto de interlocução, é dedicado, nesse sentido, a um (ou vários) poeta(s) ilustre(s) desaparecido(s), mas dedicase, igualmente, ao estabelecimento de uma rede de afinidades e concepções de escrita que pressupõem a instauração de uma comunidade (de que participam, na Divina Quimera, Baudelaire, Dante, Mallarmé, Nerval, Poe, Chopin ...).

Dois poemas de Alphonsus de Guimaraens fazem supor uma retomada da prática do elogio fúnebre, deslocando-a para uma "poética do tombeau", nos termos em discussão: "Epitáfio para o túmulo de Álvaro Viana” (a que se insere a epígrafe: "Discípulo amado") e "Pour le tombeau de Jacques D’Avray”. O primeiro foi recolhido postumamente em sua Obra completa (1960), em "Outras poesias". O segundo integra a coletânea de poemas escritos em francês Pauvre Lyre (que ainda teria sido organizada pelo poeta). Apresentando inclusive algumas imagens recorrentes, os 
dois sonetos escrevem-se rigorosamente em terceira pessoa, reduplicam a construção simbólica de um túmulo e enumeram descrições valorativas destinadas a compor o louvor que congrega (em análise neste ensaio). Curioso que ambos se abram com a mesma solicitação enfática da concorrência das Musas (conforme se descreveu anteriormente a propósito dos Broqueis e da Divina Quimera):

Musas! Este que aqui, no último sono, abraça, Braços postos em cruz, o seu próprio esqueleto, Sustinha (o Poeta é como alvo cisne que passa) Uma cítara d'oiro a gemer-lhe no peito.

(GUIMARAENS, 1960, p. 508)

E:

Muses, vous le voyez: c'est le salut des pairs.

Ci-gît le chevalier du saint Luth, douce Altesse

Du rhythme: comme une ombre étoillée, il se dresse

Bercé par l'harmonie insigne de ser vers.

(GUIMARAENS, 1960, p. 374)

Explorando a constituição de um discurso sobre a morte ao longo da trajetória poética de Mallarmé ${ }^{15}$ a partir da consideração da tradição do elogio fúnebre, Jean- Nicolas Illouz analisa as diversas situações de escrita em que a poética mallarméana estaria confrontada com a apreensão melancólica de um objeto desaparecido. Desde a homenagem a Théophile Gautier, “Toast Funèbre” (1872), passando pelos poemas tombeaux (sem esquecer as "Notes pour um tombeau d'Anatole"), muitos seriam os discursos, poemas ou homenagens em que se poderia observar a constituição de uma tanatografia mais ou menos explícita, até o que pudesse ser o estabelecimento de uma espécie de esquema geral do tombeau mallarméano. Para Illouz, nesse processo, gestos e rituais do luto seriam retomados da religião para serem reinterpretados em sua dimensão

15 Conferir: "Fragments d'un discours sur la mort: Éloge Funèbre, tombeaux et écriture du deuil dans l'oeuvre de Mallarmé”. (ILLOUZ, 2008, p. 375-390) 
estritamente humana e assim convertidos à pura poesia, em profanação poética do religioso, que seria, ao mesmo tempo sua elucidação e sua superação. O tombeau talvez fosse pensado, nesse sentido, por Mallarmé, como uma espécie de creuset (cadinho) quase alquímico em que a matéria poética das obras dos poetas desaparecidos seria posta em fusão para que se desembaraçasse pela morte, gerando na obra derivada um efeito impessoal que permitisse o advento da voz do poeta.

Que uma voz se possa constituir (ou desaparecer) a partir de um complexo cruzamento e decantação de poéticas: operação a ser perseguida nas recriações e reatualizações de rituais de fundo religioso e/ ou de execução profana (literária) que, como o elogio fúnebre, constituem grupos e sistemas de valores em partilha. Se o poeta novo ou o homem enlutado retrabalham (deformam, reformam, perturbam) o conteúdo do que pode ser mantido sob proteção em um túmulo específico, não terá sido por mais que um curioso gesto de anacronismo, em que o precursor se constitui (novo e inesperado) na página irreverente do sucessor. $\mathrm{Ou}$, como no poema de Alphonsus de Guimaraens, em que as musas reaparecem mediando a relação entre duas poéticas, de modo que um desejo de escrita se permita sonhar que pudesse ter sido desejado por aquele que o sonho primeiro despertou:

Anachronisme

(Sonnet dédicace à Paul Verlaine)

Les muses m'ont bercé dans mon berceau. J'étais

Un pauvre enfant chétif et mon âme étant vaine

Comme celle de qui, sans amour et sans haine,

Pâle, dans la pâleur de la mort, sanglotait.

Depuis, les ans s'en vont, et pour moi tout se tait.

Dans mon ciel apparut une étoile de peine...

Et j’ai pleuré. Mais toi, ô mon maître Verlaine,

Tu m’as souri, et moi, ô je le méritais! 
À toi, le maître doux, à toi toute la gloire

De mes vers parsemés d'or, d'onix et d'ivoire,

Perdus dans les sentiers augustes de la foi...

Et pourtant, si je suis ton fils et ton élève,

En te suivant, en te baisant l'âme sans trêve,

Je rêve, ami, que toi, tu as rêvé de moi!

(GUIMARAESNS, 1960, p. 373)

O poema oferecido em homenagem/elogio/dedicatória: espelho de um oferecimento prévio atualizando-se em desejos de reciprocidade.

ELOGIOS FÚNEBRES, PIEDRAS TUMULARES, SUEÑOS MUdOS: CÍRCULOS LITERARIOS Y REINVENCIÓN RITUAL ENTRE POETAS BRASILEÑOS (XIX-XX)

\section{RESUMEN}

El ensayo explora la recurrencia, entre poetas brasileños, de textos que se refieren a la práctica del elogio fúnebre, o que recuperan de modo más o menos explícito la especie tombeau, en diálogo con poetas franceses de finales del siglo XIX. El texto recupera formulaciones de Jean Michel Maulpoix para presumir un carácter colectivo primario para el poema lírico (la raíz del lirismo asentándose en la celebración) y analiza el discurso encomiástico (elevado, laudatorio, dirigido) discernible en los poemas abordados como portador de algo que no se resuelve en la expresión de un "yo", sino que parece indiciar una operación colectiva de constitución de audiencia, comunicación, contacto, reparto. El poema, un gesto de interlocución, es dedicado, en ese sentido, a un poeta ilustre desaparecido, pero se dedica, igualmente, al establecimiento de una red de afinidades y concepciones de escritura que presuponen la instauración de una comunidad.

Palabras Clave: elogio fúnebre; tombeau; comunidad. 


\section{FUNERAL PRAISES, TOMBSTONES, MUTE DREAMS: LITERARY CIRCLES AND RITUAL REINVENTION AMONG BRAZILIAN POETS (XIX-XX)}

\section{ABSTRACT}

The essay explores the recurrence among Brazilian poets of texts that refer to the practice of funeral eulogy, or that recover in a more or less explicit way the species tombeau, in dialogue with French poems of the late nineteenth century. Assuming, with Maulpoix, a primary collective character for the lyric poem (the root of lyricism based on the celebration), we analyze the commemorative discourse (high, laudatory, addressed) discernible in the poems approached as the bearer of something that is not solved in the expression of an "I", but that seems to indicate a collective operation of constitution of audience, communication, contact, sharing. The poem, gesture of interlocution, is dedicated, in this sense, to an illustrious poet disappeared, but also dedicates itself to the establishment of a network of affinities and conceptions of writing that presuppose the establishment of a community.

KEYwORDs: funeral eulogy; tombeau; community.

\section{REFERÊNCIAS}

ANTONELLI, Ellen Guilhen Barbosa. A organicidade musical de Divina Quimera (1916), de Eduardo Guimaraens. 2017. 322 f. Tese (Doutorado em Teoria e História Literária) - Instituto de Estudos da Linguagem, Universidade Estadual de Campinas, Campinas, 2017.

ARAÚJO, Paulo. Saturnino de Meireles. In: MURICY, Andrade. Panorama do movimento simbolista brasileiro. Brasília: Conselho Federal de Cultura e Instituto Nacional do Livro, 1973. p. 824. (v. 2).

BÉLANGER, Joël Castonguay. L'édification d'un Tombeau poétique: du rituel au recueil. Études Françaises, v. 38, n. 3, p. 55-69, 2002.

CRUZ E SOUSA, João. Obra completa. Rio de Janeiro: Nova Aguilar, 2000.

FERNANDES, Carlos D. Fernandes. Ante o cadáver de Cruz e Sousa. In: MURICY, Andrade. Panorama do movimento simbolista brasileiro. Brasília: Conselho Federal de Cultura e Instituto Nacional do Livro 1973. p. 641. (v. 2). 
FLEGES, Amary. Les Tombeaux littéraires en France à la Renaissance, 1500-1589. 2000. Thèse (Doctorat) - Université de Tours, 2000.

GÉNETIOT, Alain. De l'ode encomiastique au chant du monde. In:

(Dir.) Léloge lyrique. Nancy: Presses Universitaires de Nancy, 2008. p. 5-14.

GUIMARAENS, Alphonsus de. Anachronisme.(Pauvre Lyre) In: . Obra completa. Rio de Janeiro: Nova Aguilar, 1960. p.373.

GUIMARAENS, Alphonsus de. Poetas exilados. In: . Obra completa. Rio de Janeiro: Nova Aguilar, 1960

ILLOUZ, Jean-Nicolas. Fragments d'un discours sur la mort: Éloge Funèbre, tombeaux et écriture du deuil dans l'oeuvre de Mallarmé. In: GÉNETIOT, Alain. (Dir.) L'éloge lyrique. Nancy: Presses Universitaires de Nancy, 2008. p. 375-390.

MEIRELLES, Ricardo. Entre brumas e chuvas: tradução e influência literária. 2003. Dissertação (Mestrado em Teoria e História Literária) - Universidade Estadual de Campinas, Campinas, 2003.

MENESES, Castro. Cruz e Sousa. In: MURICY, Andrade. Panorama do movimento simbolista brasileiro. Brasília: Conselho Federal de Cultura e Instituto Nacional do Livro, 1973. p. 817. (v. 2).

SCHÜLER, Donaldo. Eduardo Guimaraens. Porto Alegre: Instituto Estadual do Livro, 1986.

SILVA, Joaquim Pereira da. Evocação a Cruz e Sousa. In: MURICY, Andrade. Panorama do movimento simbolista brasileiro. Brasília: Conselho Federal de Cultura e Instituto Nacional do Livro, 1973. p. 671. (v. 2).

VÍTOR, Nestor. A Cruz e Sousa. In: MURICY, Andrade. Panorama do movimento simbolista brasileiro. Brasília: Conselho Federal de Cultura e Instituto Nacional do Livro, 1973. p. 333. (v. 1).

Submetido em 26 de maio de 2019

Aceito em 25 de julho de 2019

Publicado em 15 de outubro de 2019 